\title{
Global and Regional Dynamics in Knowledge Flows and Innovation Networks
}

\author{
CHRIS VAN EGERAAT* \& DIETER F. KOGLER** \\ *Department of Geography, National University of Ireland, Maynooth, Ireland, **School of Geography, \\ Planning \& Environmental Policy, University College Dublin, Dublin, Ireland
}

Knowledge, learning and innovation are key elements in theories concerning economic development and growth. Since Schumpeter (1942) it has been recognized that the displacement of old goods or technologies by new ones, a process that is endogenously generated and also known as "creative destruction", serves as the engine of growth. Innovation, which in essence is the generation of knowledge and its subsequent application in the marketplace in the form of novel products and processes, has become the key concept in inquiries concerning the contemporary knowledge-based economy (Drucker, 1969; Bell, 1974). Geography plays a decisive role in the underlying processes that enable and support knowledge formation and diffusion activities. Place-specific characteristics are considered especially important in this context; however, more recently investigation into innovative capacity of places has also turned its attention to external knowledge inputs through innovation networks (Bunnell \& Coe, 2001; Bathelt et al., 2004), and increasingly recognize the evolutionary character of the processes that lead to knowledge creation and subsequent application in the marketplace (Boschma \& Frenken, 2006; Frenken \& Boschma, 2007). Feldman and Kogler (2010) provide an overview of the literature on the geography of innovation, including a discussion of some commonly accepted "stylized facts" in this line of inquiry. While addressing different facets of knowledge production and innovation processes, taken as a whole, the articles that make up this special issue provide an overview of the relevant topics in contemporary research concerned with the "global and regional dynamics in knowledge flows and innovation networks".

Knowledge, unlike most other economic goods, exhibits very distinctive properties. Scientific or technical knowledge that is codified, and thus is accessible in the form of published research, patent documents, etc., is regarded as having a public good character, due to its non-rivalry and non-excludability qualities. This implies that knowledge can be utilized by many users without diminishing its utility, and at the same time should 


\section{Editorial}

be available to whomever searches for it (Arrow, 1962). From a spatial perspective, local variations in the availability of knowledge exist, and in most instances explicit knowledge can be very costly to transfer from place to place. This is still true today despite the myriad of advanced telecommunication tools that allow for real-time transactions, and the fact that obtaining information appears to have become a global rather than a local process. Tacit knowledge, as opposed to freely available information, is embedded in individuals, and although manifested in practices or routines, it is not explicitly codified (Polanyi, 1966; Gertler, 2003). Also, its economic value, in most instances, is difficult to evaluate, and may differ significantly among a potential group of users.

This type of knowledge is considered to be quite spatially sensitive in terms of its transmission and diffusion, which requires extensive personal contact. The local "stickiness" of tacit knowledge (von Hippel, 1994), which can have a number of causes, is strongly determined by untraded interdependencies that exist in a place, which include routines, habits and norms, conventions of communication and interaction (Storper, 1997), resulting in cumulative-causation externalities. In particular, regular face-to-face contact that enhances trust-building mechanisms, and a low cultural or cognitive distance, including a common language and shared scientific field of inquiry among the individuals involved, are considered essential elements to facilitate and improve tacit knowledge spillover processes (Gertler, 1995). Thus, spatial knowledge "stickiness" also depends largely on the attributes of the actual information holders or seekers. For example, the lack of "absorptive capacity" (Cohen \& Levinthal, 1990) by a particular knowledge seeker could limit their ability to acquire information due to the absence of certain tools or complementary information. Overall, the regional scale dominates the field of territorial innovation systems research, mainly due to the observation that innovation processes primarily depend on local institutional capacity. Following this line of argument, it is noted that as a result of specific advantages from locally rooted institutional capacities, in the form of tacit knowledge, the regional innovation system provides an excellent framework for analysing localized learning processes (Cooke, 1996; Maskell \& Malmberg, 1999).

One methodological tool that has recently established itself as a useful approach to innovation studies is the use of social network analysis. The roots of the network concept and network theory go back to the end of the nineteenth century (Graber, 2006). For many years little attention was devoted to the role of networks in economic activity; however, since the early 1990s an increasing body of economists, economic sociologists and economic geographers have been focusing on the significance of networks as they relate to economic activity, innovation and regional development. Network theory and analysis can lead to a better understanding of innovation and territorial economic development processes (Ter Wal \& Boschma, 2008).

Knowledge production processes, and thus innovation, are guided by evolutionary patterns that can at times progress anywhere from slow and cumulative to rapid and radical. Prior knowledge inputs usually serve as the point of departure, but the path of a technological trajectory can be significantly altered if extra-local knowledge networks exist. It is accepted that "local buzz" considerably influences aspects of regional knowledge production (Storper \& Venables, 2004), but also that this can be noticeably supplemented by means of extra-local sources of knowledge (Owen-Smith \& Powell, 2004). Also, knowledge and knowing in general cannot be separated from an individual's engagement (Cook \& Brown, 1999). Thus, communities of practice, which exist in a variety of settings, may develop improvements or innovations in products, services and work practices in 
environments that have not much in common with the traditional geographic platform of economic organization. This suggests that relational proximity might be a substitute for spatial proximity (Amin \& Cohendet, 2004). However, there has to be a clear distinction between knowledge containing economic value, and content or information that does not possess these qualities. While content appears readily available, knowledge, on the other hand, is best transmitted via face-to-face interaction. It is possible for individuals to overcome the need for spatial proximity in the form of temporary agglomerations, but this usually requires frequent and trusted interaction that predominantly occurs in a collective place.

Cities are a key example of such places of knowledge exchange and creativity; they provide opportunities due to a high density of knowledge-generating activities, coupled with potential knowledge spillovers (Feldman \& Audretsch, 1999; Scott, 2006). Nevertheless, absolute geographic proximity potentially could be substituted, or complemented by a number of other proximity measures, including cognitive, organizational, social and institutional proximities (Boschma, 2005). This is especially realistic in an evolutionary framework where the focus is on aspects that drive technological trajectories along the arguments of knowledge accumulation. Here, different types of proximities may play an important role at varying points of time along the evolution of the technologies that provide the foundation for firms and industries.

The contributions to this special issue are embedded at the intersection of the dynamic processes of knowledge production and creative destruction. The first three contributions all discuss the role of global innovation networks, in the context of territorial and/or sectoral dynamics. The paper by Phil Cooke investigates the dynamic relationships in the global innovation network of the information and communication technology (ICT) sector. Of particular focus are the processes that shaped supply chain displacement of Western chipmakers by Asian competitors in the transition from the first to the second version of the Apple smartphone. The author applies the evolutionary complexity theory as a conceptual framework in order to analyse how modularization, which has taken place largely by acquisitions, was directed by spatial proximities and policies. The results indicate that there has been significant shifts in the complex and fast-changing relational space of the globalized system for producing smartphone and tablet handheld ICT devices and services.

The article by Campos Silva and Klagge deals with the evolution of a specific sector, the global wind turbine industry. Adopting an evolutionary approach, the authors analyse the organizational and spatial dynamics of the industry. Geographically, the centre of gravity of the industry has been shifting from Europe to China. The authors argue that, in search of an explanation for change, we need to move away from the traditional emphasis on innovation and learning and firm-based processes of change towards the interaction of these micro-level forces with macro-level, especially political, forces. This is convincingly illustrated with reference to China where political support was essential for establishing a domestic industry. However, the more recent development phase has been strongly influenced by firm-based strategies, notably the establishment of global innovation networks by leading Chinese turbine manufacturers.

Seamus Grimes focuses on the impact of global innovation networks on a specific territory-China. Echoing Campos Silva and Klagge, the article underlines the interaction between firm-based innovation strategies and the salience of political forces and policies. The traditional multinational model of global innovation networks, involving the generation and exploitation of intellectual property within the boundaries of the corporation, 


\section{Editorial}

has been seen to clash with the Chinese government's aspirations of industrial and economic upgrading. The article analyses China's strategy of indigenous innovation and related policies that, if successful, will have to involve a change in the structure and organization of the global innovation networks of multinational companies operating in China.

The next two contributions in this special issue investigate the evolution of regional or metropolitan knowledge economies. Kogler, Rigby and Tucker construct a US technology knowledge space over the time period 1975-2005, and subsequently analyse the evolution of urban knowledge cores in US metropolitan areas. The investigation is based on a measure of the technological proximity of technology classes that is derived from the co-classification information contained in patent documents, which in turn indicates the level of specialization of US inventions. The main findings show that individual cities exhibit a range of trajectories with respect to the specialization of their knowledge bases over the observed time period, and that higher levels of knowledge relatedness within cities are associated with faster rates of patenting per worker, which is in line with research conducted on agglomeration economies that illustrates that specialization spurs efficiency gains. Furthermore, the results also demonstrate that the changes in the coherence or the specialization of the knowledge basis of cities potentially provide insights into how knowledge relatedness is indicative of patterns of technological diversification and abandonment.

Heike Mayer, in her contribution, focuses on peripheral regional economies-or second-tier high-tech regions. In contrast to the canonical first-tier high-tech regions, growth of more peripheral regions is often fuelled by spin-off network dynamics and not by agglomeration economies. However, such processes are not guaranteed. The article shows how entrepreneurship and firm building are linked with a peripheral region's ability to grow and facilitate incubator firms, large innovative firms that provide the training ground for entrepreneurs. The article therefore underlines the importance of being sensitive to the organization, structure and culture of the existing firms in a regional economy.

The final three articles all adopt the knowledge base approach to understanding the organization of innovation networks and spatiality of knowledge flows (Asheim \& Gertler, 2005). First, Roman Martin helpfully links the knowledge base conceptualization with network theory. Different knowledge bases (analytical, synthetic and symbolic) are postulated to be associated with specific network structures, relations and geographical configurations. The social network analysis of a number of regional industries supports these ideas. In relation to geography, the data suggest that industrial networks characterized by the analytical knowledge base are only weakly constrained by geographical distance, while networks in symbolic industries are more strongly constrained, leading to more localized networks.

Van Egeraat, O'Riain and Kerr, in their contribution, assess the relevance of the knowledge base conceptualization for the symbolic knowledge base industry in the context of the Irish animation industry. Their findings contradict both the theoretically deduced postulations set out in their article and the findings of Roman Martin's article. Nearly all of the main partners, clients, temporary staff and other sources of knowledge used by the Irish companies are located overseas. The explanation for the surprising findings is sought in the role of non-geographic forms of proximity (Boschma, 2005). In addition, the study finds little support for the role of local buzz in knowledge flow. The Irish community tends to meet mainly during international events. Contributing to the global pipelines 
versus the local buzz literature (Bathelt et al., 2004), the authors contend that the local animation community "buzzes globally".

Finally, the article by Liu, Chaminade and Asheim relates to both the knowledge base and global innovation network focused articles in this special issue. The authors argue that the innovation literature tends to focus on inter-firm networks and that intra-firm networks of multinational enterprises are often ignored. This article specifically includes these intrafirm networks into the analysis. Again fruitfully applying social network analysis, the article identifies two distinct models for global innovation networks, the globally organized and locally organized model. In the process, the authors provide an important methodological contribution by integrating a spatial element in the social network analysis methodology tool set.

\section{Acknowledgements}

This special issue draws mainly on the subset of innovation focused papers presented at an international conference at the National University of Ireland, Maynooth (2012) - Networks and Flows in Economic Space. The conference was organized by the Department of Geography, as part of its 40th anniversary celebrations. The conference brought together a dozen global leaders in the fields of Economic Geography and Economics. The guest editors would like to thank the participants of the conference for their comments that helped shape the articles in this special issue. Support for the conference programme from Professor Gerry Kearns and the office of the Vice President for Research at NUIM is gratefully acknowledged. In addition, we would like to thank the Regional Studies Association, Irish branch for their financial support.

\section{References}

Amin, A. \& Cohendet, P. (2004) Architectures of Knowledge: Firms, Capabilities, and Communities (Oxford: Oxford University Press).

Arrow, K. (1962) Economic welfare and the allocation of resources for inventions, in: R. R. Nelson (Ed.) The Rate and Direction of Innovative Activity, pp. 609-625 (Princeton, NJ: Princeton University Press).

Asheim, B. \& Gertler, M. (2005) The geography of innovation, in: J. Fagerberg, D. Mowery \& R. Nelson (Eds) The Oxford Handbook of Innovation, pp. 291-317 (Oxford: Oxford University Press).

Bathelt, H., Malmberg, A. \& Maskell, P. (2004) Clusters and knowledge: Local buzz, global pipelines and the process of knowledge creation, Progress in Human Geography, 28(1), pp. 31-56.

Bell, D. (1974) The Comings of Post Industrial Society (London: Heineman).

Boschma, R. A. (2005) Proximity and innovation. A critical assessment, Regional Studies, 39(1), pp. 61-74.

Boschma, R. A. \& Frenken, K. (2006) Why is economic geography not an evolutionary science? Towards an evolutionary economic geography, Journal of Economic Geography, 6(3), pp. 273-302.

Bunnell, T. G. \& Coe, N. M. (2001) Spaces and scales of innovation, Progress in Human Geography, 25(4), pp. 569-589.

Cohen, W. M. \& Levinthal, D. A. (1990) Absorptive capacity: A new perspective on learning and innovation, Administrative Science Quarterly, 35(1), pp. 128-152.

Cook, D. N. \& Brown, J. S. (1999) Bridging epistemologies: The generative dance between organizational knowledge and organizational knowing, Organization Science, 10(4), pp. 381-400.

Cooke, P. (1996) Regional innovation systems: An evolutionary approach, in: H. Baraczyk, P. Cooke \& R. Heidenreich (Eds) Regional Innovation Systems, pp. 1-18 (London: UCL Press).

Drucker, P. F. (1969) The Age of Discontinuity: Guidelines to Our Changing Society (New York: Harper and Row).

Feldman, M. P. \& Audretsch, D. B. (1999) Innovation in cities: Science-based diversity, specialization, and localized competition, European Economic Review, 43(2), pp. 409-429. 


\section{Editorial}

Feldman, M. P. \& Kogler, D. F. (2010) Stylized facts in the geography of innovation, in: B. Hall \& N. Rosenberg (Eds) Handbook of the Economics of Innovation, pp. 381-410 (Oxford: Elsevier).

Frenken, K. \& Boschma, R. A. (2007) A theoretical framework for evolutionary economic geography: Industrial dynamics and urban growth as a branching process, Journal of Economic Geography, 7(5), pp. 635-649.

Gertler, M. S. (1995) 'Being there': Proximity, organization, and culture in the development and adoption of advanced manufacturing technologies, Economic Geography, 71(1), pp. 1-26.

Gertler, M. S. (2003) Tacit knowledge and the economic geography of context, or the undefinable tacitness of being (there), Journal of Economic Geography, 3(1), pp. 75-99.

Graber, G. (2006) Trading routes, bypasses and risky intersections: Mapping the travels of networks, progress human geography, Progress in Human Geography, 30(2), pp. 163-189.

von Hippel, E. (1994) Sticky information and the locus of problem solving: Implications for innovation, Management Science, 40(4), pp. 429-439.

Maskell, P. \& Malmberg, A. (1999) Localised learning and industrial competitiveness, Cambridge Journal for Economics, 23(2), pp. 167-186.

Owen-Smith, J. \& Powell, W. W. (2004) Knowledge networks as channels and conduits: The effects of spillovers in the Boston biotechnology community, Organization Science, 15(1), pp. 5-21.

Polanyi, M. (1966) The Tacit Dimension (New York: Doubleday).

Schumpeter, J. (1942) Capitalism, Socialism and Democracy (New York: Harper).

Scott, A. J. (2006) Entrepreneurship, innovation and industrial development: Geography and the creative field revisited, Small Business Economics, 26(1), pp. 1-24.

Storper, M. (1997) The Regional World: Territorial Development in a Global Economy (London: Guilford Press).

Storper, M. \& Venables, A. J. (2004) Buzz: Face-to-face contact and the urban economy, Journal of Economic Geography, 4(4), pp. 351-370.

Ter, Wal A. \& Boschma, R. (2008) Applying social network analysis in economic geography: Theoretical and methodological Issues, Annals of Regional Science, 43(3), pp. 739-756. 
Copyright of European Planning Studies is the property of Routledge and its content may not be copied or emailed to multiple sites or posted to a listserv without the copyright holder's express written permission. However, users may print, download, or email articles for individual use. 